\title{
Los conceptos de simulación y disimulación en la representación de la locura en El cuerdo loco, de Lope de Vega*
}

\section{Ana Aparecida Teixeira de Souza}

\section{RESUMEN}

El objetivo de este artículo es demostrar cómo Lope de Vega construye la locura fingida del príncipe Antonio, protagonista de la obra dramática titulada El cuerdo loco (1605), a partir de los conceptos de simulación y disimulación, los cuales formaban parte de los códigos de conducta de los siglos XVI y XVII.

En este artículo, el estudio tiene como preocupación la representación de la figura del loco fingido en la comedia El cuerdo loco (1605). El argumento de esta comedia gira en torno a muchas intrigas políticas del universo de una corte, situada en el reino imaginario de Albania. En este contexto, el príncipe Antonio simula locura cuando descubre que algunos integrantes de su casa real habían organizado un plan para destituirlo del poder monárquico, lo cual le permite decirles algunas verdades y, a la vez, cambiar el juego político a su favor.

A fin de que se pueda demostrar cómo Lope de Vega construye la locura fingida del príncipe Antonio, este trabajo se apoya en los conceptos de simulación y disimulación, los cuales formaban parte de los códigos de conducta de los siglos XVI y XVII. Estos dos conceptos fueron explicitados en el tratado La disimulación honesta (título original Della dissimulazione onesta, de 1641), del italiano Torquato Accetto, que se dedica a las orientaciones sobre la necesidad y las técnicas de ocultación de la verdad (HANSEN, 1996, p. 89). Para Accetto (2005, p. 109), la "disimulación es la acción de no hacer ver las cosas como son. Se simula lo que no es, se disimula lo que es". Con la intención de ejemplificar esta definición, el tratadista italiano se apoya en el verso del poeta Virgilio, donde éste describe la simulación de la esperanza y la disimulación del dolor de Eneas: "En su inmensa congoja el rostro esperanza" (ACCETTO, 2005, p. 109). A pesar de que la simulación y la disimulación

\footnotetext{
* Es importante aclarar que parte de este artículo fue presentado oralmente en el Simposio Hispano-Brasileño. Jóvenes Hispanistas del Siglo de Oro, celebrado en la Universidade de São Paulo (Brasil), en julio de 2013.
} 
caminan muchas veces juntas, en muchos casos, es necesario reconocer que cada una se destina a un determinado fin y que cada una posee un determinado sentido moral. Según las aclaraciones de la investigadora Maria Augusta Vieira, se comprende que "la disimulación honesta encubre una verdad mientras que la simulación exhibe una mentira" (VIEIRA, 2007, p. 91).

Aunque el tratado de Accetto pertenezca al seicento italiano, merece la pena decir que tanto la simulación como la disimulación se hicieron presentes en el ámbito español quinientista. Como ejemplo, sobresale la obra de Luis Zapata Chaves, titulada Miscelánea. Silvia de casos curiosos (1592), que presenta una serie de dichos y escenas de la vida poética, social y política de su tiempo, es decir, el período que comprende el reinado de Felipe II. En esta obra hay un capítulo específico sobre la cuestión del fingimiento, bajo el título "De disimulación y fingimiento", cuyo objetivo es hacer una breve exposición de los beneficios que uno puede conseguir a través de la disimulación y del fingimiento, sobre todo en lo que se refiere a la convivencia saludable en sociedad. De los cuentos narrados por Luis Zapata, se destaca la historia de Ruiz Díez de Mendonza, que "estaba en aprobación del hábito de Santiago en el Convento de Uclés" y como "andaba muy a malas con el Prior" (ZAPATA, 1859, p. 116) se finge de loco para tener la oportunidad de darle un bofetón, hecho que, si lo hiciera lúcido, perdería dicho hábito y sería castigado por el Emperador. Para ello, Ruiz Díez de Mendonza "comienza a dar risadas sin tiempo, a hacer ademanes excusados, a andar imaginativo, a hablar y responder sin propósitos, y a hacer todas las cosas, con que él ya persuadió al convento que estaba loco" (ZAPATA, 1859, p. 116). Con el apoyo de la máscara fingida de la locura, consigue alcanzar su propósito, dándole el tan esperado bofetón al Prior, sin sufrir ningún tipo de daño.

La locura fingida de Ruiz Díez es muy similar a la del príncipe Antonio, pues ambos utilizan el artificio del fingimiento para conseguir un determinado fin. En El cuerdo loco, la simulación de la locura es la manera con la cual el príncipe consigue proteger a su reino de un golpe político. El conflicto en la comedia surge cuando el conde Dinardo le propone a Rosania, madrastra del príncipe y viuda de su padre, que asuma para sí el reino de Albania. Para convencerla, Dinardo se apoya en la retórica de los afectos, mostrándole que perdería su posición social en la corte y, con ello, sus privilegios reales, ya que el príncipe Antonio 
“querrá casarse, y en trayendo / nuera a tu casa, ha de querer mandarte; / y él, tu imperio también aborreciendo, / ha de querer de su palacio echarte" (VEGA, 1922, p. 17). Frente a este infortunio, Dinardo le dice que, si sigue sus consejos, conseguirá mantener su posición privilegiada en la corte, como en estos versos: "serás señora de ellos, muerto Antonio / y yo tu esclavo en dulce matrimonio" (VEGA, 1922, p. 18). Claro está que Dinardo la manipula para poder participar activamente en las funciones políticas del reino de Albania. Rosania acepta la propuesta de Dinardo, alertándole que no era bueno matar al príncipe, porque colocaría al reino en peligro, el cual estaría disponible para ser conquistado por cualquier otro emperador. Así, le sugiere envenenar a Antonio con una bebida que lo vuelva loco, de modo que pudieran asumir el reino por causa de la enajenación mental del gobernante. Para ello, le encargan la misión al cocinero Roberto, que todas las mañanas le prepara la epítima, bebida utilizada para prevenir la melancolía ${ }^{1}$, al príncipe. Roberto tiene un papel importante en la obra, pues le revela al príncipe los planes de Rosania y Dinardo. Asimismo, le propone a Antonio que simule locura para engañar a los traidores. Conforme observa Jonathan Thacker (2004, p. 471), el cocinero reconoce que la locura fingida es un medio por el cual el príncipe tendrá condiciones de poner en evidencia la verdad ante la mentira de sus enemigos. Como resultado de tal actitud, Roberto representa exactamente las funciones atribuidas a los personajes que hacen el papel del gracioso en la comedia nueva, ya que este tipo de personaje "es sugeridor de tramas y el que pone remedio en los males" (MONTESINOS, 1951, p. 62).

El príncipe se admira de la invención de Roberto y tiene la perspicacia de reconocer, como todo discreto, la necesidad de incorporar la máscara del loco fingido, con el fin de esperar el tiempo oportuno para revelar su fingimiento, vengarse de sus traidores y recuperar su trono. Desde el punto de vista contemporáneo, suena raro que un rey adopte la simulación de la locura para proteger a su reino. Sin embargo, cuando se consideran los códigos de civilidad de los siglos XVI y XVII, se percibe que la actitud del príncipe Antonio

\footnotetext{
${ }^{1}$ Dicha enfermedad es ocasionada por la bilis negra que se convierte en un fluido tóxico que, según Sebastián Covarrubias (2006, p. 1264), ocasiona la alienación de la mente. En las explicaciones de Belén Atienza (2009, p. 127), el desequilibrio de los humores puede llevarlo a uno a la locura. Como el Príncipe Antonio ejercía la función de monarca, tenía la preocupación de prevenir el humor melancólico, pues no era muy adecuado para aquellos que se encuentran en el poder, ya que les prejudica el raciocinio y, por supuesto, el control de sí mismo, ya que la melancolía se opone al "orden de la virtud y la templanza, por las cuales el ser humano se hace dueño de sí mismo" (ATIENZA, 2009, p. 127).
} 
puede ser considerada como discreta, partiendo del principio de que el discreto, como observa el profesor João Adolfo Hansen (1996, p. 86), es capaz de fingir la falta de ingenio y prudencia o la vulgaridad y la locura. Es justamente por ser un tipo discreto que Antonio se vale de su conocimiento político y social para producir una nueva representación, con vistas a convencer a los demás de que, de hecho, había sido envenenado con la bebida y, como consecuencia, había perdido el juicio.

Para ofrecer verosimilitud a su condición de alienado, Antonio dramatiza los efectos colaterales de dicho veneno, haciendo "mal rostro", es decir, un rostro desfigurado. En términos aristotélicos, la expresión corporal del príncipe corresponde a una fealdad física. Y sobre esto es bien sabido, con la Poética, que la "máscara cómica es algo feo y deforme" (ARISTÓTELES, 2007, p. 45), de modo que cuando el príncipe asume dicho disfraz cómico, produce en escena la violación del decoro, ya que deja de comportarse de acuerdo con su posición social. El propio Lope, en su preceptiva dramática Arte Nuevo de hacer comedias (1609), comenta que "Si hablare el rey, imite cuanto pueda la gravedad real" (VEGA, 2002). Es justamente por no seguir con las convenciones que el príncipe construye otra representación: la de un loco. Segundo Roger Chartier (1998, p. 62) la cuestión de la apariencia es un principio fundamental de la sociedad cortesana, pues la persona es identificada a partir de la representación que produce ante la mirada ajena. Volviendo al siglo XVII, se reconoce con Baltasar Gracián, por intermedio de El Discreto, que "La mayor sabiduría, hoy encargan políticos que consiste en hacer parecer. Saber y saberlo mostrar es saber dos veces" (GRACIÁN, 1993, p. 141). En el caso en cuestión, el príncipe Antonio incorpora los signos de la locura y adopta la manera de comportarse de un loco, ya sea en las palabras o en las acciones, para llevar a cabo el juego de la simulación y la disimulación.

Como ejemplo, se puede poner en evidencia la escena en que Antonio, bajo la máscara simulada del loco fingido, dice muchas verdades sin que nadie se las tome en serio:

$\begin{array}{ll}\text { DINARDO } & \text { Yo, ¿quién soy? } \\ \text { ANTONIO } & \text { Un gran traidor. } \\ \text { DINARDO } & \begin{array}{l}\text { Esto que dice entended, } \\ \text { mirad qué mayor locura. }\end{array} \\ \text { ROSANIA } & \begin{array}{l}\text { Pues aún más habéis de ver. } \\ \text { Y yo, ¿̇quién soy? } \\ \text { ANTONIO }\end{array}\end{array}$




$\begin{array}{ll} & \text { de ese traidor. } \\ \text { ROSANIA } & \text { ¿Qué más prueba? } \\ \text { ANTONIO } & \text { Todas aprendiste de Eva } \\ & \text { a quitar al hombre el ser. } \\ & {[\ldots]} \\ \text { LEONILDO } & \begin{array}{l}\text { Privado está de sentido. } \\ \text { (VEGA, 1922, p. 58) }\end{array}\end{array}$

Antonio, al ser cuestionado por los conspiradores, les contesta exactamente con aquello que le preguntan, revelándoles lo que realmente son. Debido a su supuesta condición de alienado, los demás no reconocen el fingimiento de su locura, lo que puede ser confirmado cuando Leonildo dice que el príncipe: "Privado está de sentido". La actitud del príncipe pone de relieve el pensamiento recurrente en el ámbito popular, pues, conforme comenta Gonzalo Correa, en su Vocabulario de refranes y frases proverbiales (1627), se entendía que "Cuando se dice a uno la pura verdad, como en burlas, de manera que él no la cree, sino lo contrario, y queda engañado" (GONZALO CORREA, 1906, p. 523). En términos teatrales, Antonio utiliza el recurso dramático "engañar con la verdad", que había sido presentado por Lope de Vega en su Arte nuevo. Según Juan Manuel Rozas (1976), se trata de una técnica que, en líneas generales, contribuye al suspense de la acción, que era muy apreciado por el público de los corrales de comedias. Ya decía Pinciano, en su Philosophía antigua poética (1596), que los engaños son motivos de risa: ¿qué más de reír de ver los enredos de una alcahueta o rufián marañados para engañar al uno y al otro?" (PINCIANO, 1998 , p. 384).

Asimismo, es posible sugerir, a partir del ámbito cultural de los siglos XVI y XVII, que Lope, en el fragmento destacado, establece una conexión con una de las características erasmianas, considerando que, para Erasmo, en su Elogio de la locura, "los estúpidos son los únicos que dicen la verdad" (ROTTERDAM, 2011, p. 253) y no son censurados por ello. Como el príncipe Antonio se presenta bajo la máscara de la locura, los demás no lo condenan, sino lo contrario, se divierten con la situación. Dinardo, por ejemplo, es uno de los que se admiran de la invención del príncipe, cuando dice: “iQué notable enloquecer!” (VEGA, 1922, p. 52). Para Jonathan Thacker (2004, p. 472), en un mundo en el cual todos hayan enloquecido, queda a la figura del loco cuerdo la función de proveer un censo de proporción, a partir de un discurso sobre la verdad, frente a los disparates de aquellos que se dicen poseedores de la razón. 
Para llevar a cabo el juego de la simulación y la disimulación, Antonio crea un lenguaje de difícil codificación, muy propio de los locos dotados de agudeza. Según las consideraciones de Montesinos, en la representación de la locura fingida, los personajes "tienen que extremar sus locuras o fingir un paroxismo para no ser descubiertos" (MONTESINOS, 1922, p. 167). Lo que hace Antonio es pronunciar un discurso metafórico, tal como se puede ver en el ejemplo a seguir:

$\begin{array}{ll}\text { ANTONIO } & \text { No prendáis a Deyanira, } \\ \text { advertid que Hércules viene. } & \text { Yo soy Hércules, que pienso } \\ & \text { matar alguna serpiente, } \\ & \text { cuando a mí salvo lo intente, } \\ & \text { y así os doy mi reino a censo. } \\ & \text { (VEGA, 1922, p. 52) }\end{array}$

Aquí, Antonio sustituye a Lucinda, que en la comedia hace el papel de su amada, y a sí mismo, por las figuras mitológicas Deyanira y Hércules, respectivamente. Como es bien sabido, Lope de Vega tenía la costumbre de hacer alusión a muchos de los personajes de la mitología grecorromana en sus comedias. En El cuerdo loco, el dramaturgo se refiere a Deyanira que, en el libro IX de las Metamorfosis de Ovidio (2011, p. 509), es caracterizada como "la más hermosa de las jóvenes y envidiable esperanza de los muchos pretendientes", de quien Hércules se había enamorado. En lo que se refiere a dicho héroe, Ovidio cuenta que su segundo trabajo fue estrangular a una serpiente de varias cabezas, venciéndola. $A$ partir de este mito, el príncipe Antonio disimula sus verdaderas intenciones, pues, por medio de un lenguaje alegórico, oculta que posee una fuerza semejante a Hércules y que, debido a eso, es plenamente capaz de vengarse de los traidores, que son representados metafóricamente a través de una serpiente. En este sentido, se puede establecer una posible conexión con el precepto de Torquato Accetto (2005, p. 26), cuando éste defiende la idea de que la práctica de la disimulación está íntimamente relacionada a la noción de "acomodarse a la necesidad", es decir, a la adecuación de la ocasión.

Siguiendo esta línea de pensamiento, se puede considerar al personaje Antonio como prudente, pues, como diría Baltasar Gracián (1993, p. 131), reconoce la ocasión exacta de manipular su representación fingida a su favor. Un gran ejemplo es cuando les revela a los albaneses que estaba simulando locura. Para ello, les cuenta su historia, por medio de un 
romance, a fin de revelarles que el objetivo de su farsa era garantizar la protección del reino. Con ese discurso, el príncipe demuestra lucidez, porque tiene la prudencia para gobernar a su reino, frente a la intriga política de sus enemigos. La actitud del príncipe demuestra lo que Saavedra Fajardo había reflexionado, en Empresas políticas o Idea de un príncipe político cristiano (1640), sobre la educación y formación de un futuro monarca, ya que "las artes de reinar son las más difíciles y peligrosas habiendo de pender de uno solo el gobierno y la salud de todos" (SAAVEDRA FAJARDO, 1845, p. III). De hecho, el príncipe Antonio prueba, a través de su discurso, ser el responsable de garantizar la armonía política de su Estado, llevándolo a optar por un juego de apariencias, en el que se muestra el mejor jugador, ante la posición de sus enemigos, Rosania y Dinardo. Este resultado positivo se debe al hecho de que con su locura simulada consigue disimular su verdadera intención, que era la de reestablecer su posición como monarca y el orden del cuerpo político de su reino. Con ello, engaña a los que habían pensado estar engañándolo, tal como está expuesto en los versos que Antonio dirige a su enemigo:

ANTONIO

¿Ves como tú eres loco y yo

[soy cuerdo?

Pues ves al cielo, duque, con la vara de su justicia, que indignaste tanto, y me ves a mí que a ejecutarla vengo (VEGA, 1922, p. 124)

Como se ve, Lope pone en escena el tema del "engañador engañado", que había sido muy utilizado en el teatro del siglo XVII, y que sigue en la misma línea de la técnica de "engañar con la verdad". Es importante decir que es a través de este recurso que ocurre el desenlace de la acción, pues todas las "burlas" del príncipe fueron convertidas en "veras", reestableciendo el orden natural de la comedia. Dicho de otro modo, el equilibrio primero de la obra se garantiza cuando los traidores son debidamente castigados por la ley del honor - Rosania y el duque son desterrados del reino de Albania - y cuando los demás integrantes de la corte, que habían sido manipulados anteriormente, se dan cuenta de que todo no pasaba de un terrible engaño, reconociendo, de esta forma, el valor del príncipe Antonio, como se puede comprobar en el discurso de Próspero: "Señor, tú eres mi rey, tú eres mi príncipe; / si sabes que engañado te he ofendido, / por tu misma piedad perdón te pido" 
(VEGA, 1922, p. 124). El orden también se garantiza cuando se reconoce, a partir de las consideraciones de Jonathan Thacker (2004, pp. 470-474), que la experiencia vivida por el príncipe Antonio durante la simulación de la locura funciona como un medio de aprendizaje, pues adquiere consciencia de que puede desempeñar su papel, como monarca, con más sabiduría, sin la necesidad de abusar de su poder político.

A partir de lo comentado en este artículo, se pueden sacar algunas conclusiones. En primer lugar, se observa que los preceptos de simulación y disimulación, presentes en las prácticas sociales de los siglos XVI y XVII, se convierten en el teatro lopesco en recurso dramático para la puesta en escena de la representación de la vida cortesana. En segundo lugar, estos dos conceptos contribuyen de manera magistral a la complicación de la trama. Y, por último, señalar que Lope de Vega, por medio de la simulación de la locura, consigue crear un juego ilusorio, que es justamente uno de los principales anhelos del teatro español del siglo XVII.

Artigo submetido para publicação em 07 de abril de 2014.

Artigo aceito para publicação em 15 de dezembro de 2014.

\section{Referencias bibliográficas}

ACCETTO, Torquato. La disimulación honesta. Trad. Sebastián Torres. Buenos Aires: El cuenco de la Plata, 2005.

ARISTÓTELES. Poética. Ed. Alicia Villar Lecumberri. Madrid: Alianza Editorial, 2007.

ATIENZA, Belén. El loco en el espejo. Locura y melancolía en la España de Lope de Vega. Amsterdam-New York: Rodopi, 2009.

CHARTIER, Roger. "Representar la identidad. Proceso de civilización, sociedad de corte y prudencia”. In: Escribir las prácticas: discurso, práctica, representación. Ed. Isabel Morant Deusa. Valencia: Fundación Cañada Blanch, 1998, pp. 61-72.

CORREAS, Gonzalo. Vocabulario de refranes y frases proverbiales y otras fórmulas comunes de la lengua castellana en que van todos los impresos antes y otra gran copia. Madrid: Establecimiento tipográfico de Jaime Ratés, 1906. 
GRACIÁN, Baltasar. El Discreto. In: Obras completas II. Madrid: Biblioteca Castro, 1993, pp. 91-199.

HANSEN, João Adolfo. "O Discreto". In: Libertinos libertários. Org. Adauto Novaes. São Paulo: MIC-FUNARTE / Companhia das Letras, 1996, pp.77-102.

MONTESINOS, José F. "Algunas observaciones sobre la figura del donaire en el teatro de Lope de Vega". In: Estudios sobre Lope. México: El colegio de México, 1951, pp. 13-70.

OVIDIO. Metamorfosis. Edición de Consuelo Álvarez y Rosa María Iglesias. Madrid: Ediciones Cátedra, 2011.

ROTTERDAM, Erasmo de. Elogio de la Locura. Ed. Jordi Bayod y Joaquim Parellada. Madrid: Editorial Gredos, 2011.

ROZAS, Juan Manuel. Significado y doctrina del arte nuevo de Lope de Vega. Alicante: Biblioteca Virtual Miguel de Cervantes, $2002 . \quad$ Fuente: http://www.cervantesvirtual.com/obra-visor/significado-y-doctrina-del-arte-nuevo-de-lopede-vega-0/html/ff8d7e8e-82b1-11df-acc7-002185ce6064 6.html\#l 1. Accesado el 24/02/2012.

SAAVEDRA FAJARDO, Diego. Empresas políticas o Idea de un príncipe político cristiano. Barcelona: Imprenta de D. Juan Oliveres, 1845.

THACKER, Jonathan. “Lope de Vega, El cuerdo loco, y 'la más discreta figura de la comedia'. In: Bulletin of Hispanic studies, Liverpool, Vol. 81, №. 4, 2004, pp. 463-479.

VEGA, Lope de. Arte nuevo de hacer comedias. Ed. Juan Manuel Rozas. Alicante: Biblioteca Virtual Miguel de Cervantes, 2002. Fuente: http://www.cervantesvirtual.com/obravisor/arte-nuevo-de-hacer-comedias-en-este-tiempo--0/html/ffb1e6c0-82b1-11df-acc7 002185ce6064 2.htm|\#I 1 . Accesado el 24/02/2012.

VEGA, Lope de. El Cuerdo Loco. Teatro Antiguo Español IV. Ed. José F. de Montesinos. Madrid: Centro de Estudios Históricos, 1922.

VIEIRA, Maria Augusta da Costa. "Discreción y simulación como prácticas de representación en el celoso extremeño". In: Actas del XV Congreso de la Asociación Internacional de Hispanistas. Monterry: Fondo de Cultura Económica, 2007, pp.87-97.

ZAPATA, Luis. Miscelánea. In: Memorial Histórico Español: Colección de documentos, opúsculos y antigüedades que publica la Real Academia de la Historia. Tomo XI. Madrid: Imprenta Nacional, 1859. 